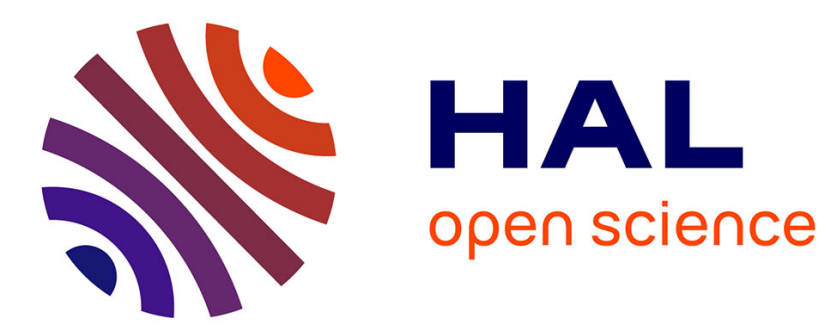

\title{
Protecting marine biodiversity beyond national jurisdiction: a penguins' perspective
}

Jean-Baptiste Thiébot, Magali Dreyfus

\section{To cite this version:}

Jean-Baptiste Thiébot, Magali Dreyfus. Protecting marine biodiversity beyond national jurisdiction: a penguins' perspective. Marine Policy, 2021, Marine Policy, 131, 10.1016/j.marpol.2021.104640 . hal-03081931

\section{HAL Id: hal-03081931 https://hal.univ-lille.fr/hal-03081931}

Submitted on 8 Dec 2021

HAL is a multi-disciplinary open access archive for the deposit and dissemination of scientific research documents, whether they are published or not. The documents may come from teaching and research institutions in France or abroad, or from public or private research centers.
L'archive ouverte pluridisciplinaire HAL, est destinée au dépôt et à la diffusion de documents scientifiques de niveau recherche, publiés ou non, émanant des établissements d'enseignement et de recherche français ou étrangers, des laboratoires publics ou privés. 
1 2

3

4

5 Jean-Baptiste Thiebot $^{1}$, Magali Dreyfus ${ }^{2}$

6

7

8

9
10 11 .

\section{6} 8

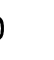
1

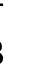

Running title: Penguins' transboundary movements tracking

\section{Acknowledgements}

The authors declare they have no conflict of interest. 3 figure or table should be considered equal to 300 words."

\author{
Number of words: 7951
}

Protecting marine biodiversity beyond national jurisdiction: a penguins' perspective

'National Institute of Polar Research, 10-3 Midori cho, Tachikawa, 190-8518 Tokyo, Japan, jbthiebot@gmail.com ${ }^{2}$ CNRS, CERAPS-Lille University, 1 place Déliot, CS 10629, 59024 Lille, France, magali.dreyfus@univ-lille.fr

Keywords (10): Area-Based Management Tools (ABMTs), Areas Beyond National Jurisdiction (ABNJ), Exclusive Economic Zone (EEZ), high seas, marine policy, migration, fisheries, at-sea distribution, endangered species,

"Perspectives articles should not exceed 8000 words. Word counts include text, references, figures and tables. Each 
2 figure or table should be considered equal to 300 words."

3 Number of words: 7951

4

\section{ABSTRACT}

6 The expansion of human activities in offshore maritime regions has outpaced the development of scientific

7 knowledge and cooperative governance across these areas beyond national jurisdiction (ABNJ). In this context,

8 current negotiations by the United Nations aim for an international legally-binding instrument to improve

9 governance and sustainable use of biodiversity in ABNJ. Penguins are among the most threatened seabird groups today, notably at sea from fisheries and oiling. Here, we examine the available information on penguin movements and evaluate their use of ABNJ to reveal ecologically significant areas. We highlight that in most of the 18 extant penguin species, the birds may undertake spectacular migrations, seasonally or throughout life-cycle stages. Longrange movements were reported in 16 species, with trans-jurisdictional distribution in 14 species, including 13 in ABNJ. Species richness in ABNJ varied extensively according to oceanic region, but less according to season. We propose that the new treaty may overcome some of the current challenges to penguin conservation, notably by creating an authority able to designate large protected areas in ABNJ, by further promoting the precautionary approach to extraction activities, and by developing technology transfer to effectively monitor ocean uses. instrument aiming to preserve a common heritage of mankind. 
22

Animals with long-range movements are exposed to contrasting degrees of protection and threats as they travel across geographic regions and countries' jurisdictions [1]. Such transboundary movements may thus challenge, or promote, the implementation of adequate strategies for biodiversity conservation [2]. In the marine environment, political boundaries exist in the form of Exclusive Economic Zones (EEZs), which include waters out to generally 200 nautical miles $(370.4 \mathrm{~km})$ from a State's shoreline. As legally defined by the 1982 United Nations Convention on the Law of the Sea (UNCLOS), EEZs provide exclusive rights to the coastal State for the exploitation and management of local marine resources. Importantly, further offshore from EEZs are the areas beyond national jurisdiction ( $\mathrm{ABNJ}$, the 'high seas'), which are recognized as global commons under the UNCLOS. These vast areas represent $64 \%$ of the ocean's surface and $95 \%$ of its volume, and opposite to the EEZs they lack a comprehensive governance structure [3,4]. This deficiency is especially concerning as the recent expansion of anthropic activities in ABNJ has outpaced the development of scientific research and cooperative governance in these areas $[5,6]$.

Area-based management tools (ABMTs), including marine protected areas (MPAs), are widely recognized as key instruments to help conserving and restoring biodiversity. Studies highlighted the need to design and implement a network of such protected areas, including in the high seas, to adequately preserve marine migratory species currently threatened with extinction [7]. Yet States face legal challenges to create and manage such ABMTs in ABNJ $[8,9]$. In this context, the UN General Assembly decided to develop an international legally-binding instrument (ILBI) under the UNCLOS, on the conservation and sustainable use of marine biological diversity of ABNJ (UN resolution 69/292 of 19 June 2015). Intergovernmental Conferences were convened to elaborate the text of a treaty (UN resolution 72/249 of 24 December 2017), with the aim of developing the instrument as soon as possible.

Progress in environmental negotiations can be hindered by several aspects of scientific uncertainty including gaps in knowledge, as shown by social sciences $[10,11]$. Therefore, gathering available information on transboundary movements may improve the relevance of adopted measures, by highlighting specific needs in conservation policy to address in this treaty [2]. Over the past decades, substantial advances have been made in our understanding of marine wildlife movements in the high seas thanks to the development of electronic tracking devices. A variety of marine vertebrates encompassing fishes, sharks and cetaceans were documented migrating across very large scales beyond EEZs; even more remarkably, this was also the case for marine animals constrained to return ashore for breeding, such as sea turtles, seals and seabirds [1,7, 12]. Penguins (Sphenisciformes) are, with albatrosses and petrels (Procellariiformes), the most threatened seabird group [13], facing a number of cumulative perils to their conservation both on land and at sea. The most documented at-sea threats encompass pollution (notably oiling), fishing (through both bycatch and resource competition), and climate change, all of which may affect penguins in their nearshore and/or offshore habitats [14, 15]. 
One could expect the movement range of penguins to be reduced compared to other marine vertebrates, for three reasons. First, penguins are constrained in the extent of their at-sea provisioning trips by frequent returns to their nest during the breeding season, unlike fishes, sharks, cetaceans and sea turtles. Second, unlike flying seabirds which may sustain high speeds aloft and accordingly distribute over considerable ranges (e.g., [1]), penguins' locomotion by swimming may minimize their movement radius. And third, penguins are unique among seabirds in that they remain out of water when moulting, which potentially constrains their at-sea range after breeding. Yet, case studies showed that penguins may, at least seasonally, migrate over unexpectedly large scales, across maritime boundaries of the southern hemisphere (e.g., $[16,17,18]$. Such observations question the overall extent to which penguins may exploit the high seas, where they currently lack effective protection from human activities.

Three decades of at-sea tracking studies on penguins across nearly all species, now provide a relevant body of knowledge to address this question in the context of conservation policy [19]. The objectives of this paper are thus to examine, for each of the 18 extant penguin species, whether the birds are known to perform transboundary movements across EEZs and/or to the ABNJ; and if yes, in which region(s) and season(s). These results aim to inform stakeholders on the extent to which penguins (1) may reveal ecologically significant areas in the high seas, and (2) may promote and in turn benefit from the development of an ILBI for the conservation of marine biodiversity in ABNJ.

\section{Methods}

\section{Literature search}

For each penguin species, publications were searched in Google Scholar between December 2019 and July 2020 using the combined keywords "at-sea", "distribution", and the species names. Papers referenced in the accessed publications were also examined. Importantly, while this paper could not provide an exhaustive review of penguin movement studies, we were particularly interested in examining those showing large-scale movements, in each species. Studies mostly relied on telemetry techniques to track the penguins' at-sea distribution, but direct observations from ship-based surveys were also included. Records of vagrant or dead birds ashore were not considered relevant here, as these may indicate aberrant, non-viable movements for the populations, with uncertain path. For example, juvenile northern rockhopper penguins Eudyptes moseleyi banded on Amsterdam Is. (southern Indian Ocean) were found dead on Australian coasts [20], but as the birds might have died before crossing jurisdictions this did not constitute adequate evidence for trans-EEZ movements here.

\section{Distribution versus jurisdictions}

Georeferenced contours of EEZs (version 11: 2019-11-18) were downloaded from the Marine Regions portal: http://www.marineregions.org/downloads.php. The penguin distributions' outermost coordinates were read from the mapped locations, or as indicated in the text. These coordinates were then overlaid on the EEZ contours. For each species, publications were listed showing cases of (1) distribution range greater than the maximal width of an EEZ 
$(370.4 \mathrm{~km})$, mirroring the capacity for the birds to potentially reach the high seas; (2) movements reaching other EEZ(s); and (3) evidence for use of ABNJ by the studied animals. However, since it was not always possible to accurately examine the birds' individual distribution from the literature, only the clear-cut cases were used here. It is thus acknowledged that other studies may exist that would bring further evidence for transboundary movements in each species, including cases when the borders were crossed by only a small geographical extent.

Besides, disputes exist between countries regarding the sovereignty of islands, and this paper does not take any party in these disputes. To recognize that such cases may translate into distinct biodiversity management regimes between regions, the EEZ around any disputed territory was considered as that of a third-party nation. Finally, under the Antarctic Treaty System, no national claim is recognized on Antarctic waters; the EEZ surrounding the Antarctic continent was hence considered as a single, continuous and distinct one in this study.

\section{Penguins' life-cycle stages}

During breeding, penguins regularly return ashore to feed their offspring and/or switch duties with their mate (reviewed in [21]). Accordingly, breeding penguins undertake typically short foraging trips lasting from less than a day (notably during chick-rearing) to a few weeks. In contrast, outside the breeding period penguins generally remain at sea for months (hence potentially ranging further offshore), and particularly during two phases of their life cycle. First, when juvenile birds disperse after fledging and until their first return, often the following year. Second, between breeding seasons, when adult penguins generally make a long seasonal retreat to sea, typically spanning winter across species and revolving around the moult. In some species however, adult penguins regularly return ashore throughout their non-breeding period. In this paper we separated penguin movements according to three lifecycle stages: juvenile dispersal, and adults' breeding (comprising incubation, brood-guard and chick-rearing phases) and non-breeding (comprising pre- and post-moult phases) periods.

\section{Unavoidable biases}

It was unavoidable that depending on the regional coastline layout, penguins from one study site had uneven chances to cross jurisdictions compared to others. Cases include (1) whether there was one or several EEZs along the regional coastline (e.g., single EEZ around Australia versus several contiguous EEZs around southern Africa); (2) uneven distances from each study site to the closest border along that coast (e.g., birds from northern Argentina are closer to Uruguay's EEZ, than those from central localities); (3) EEZs extending further offshore due to neighbouring domestic islands, potentially containing even long-ranging distributions (e.g., New Zealand's subantarctic islands stretching out southward); and (4) a reduced EEZ width, due to the presence of a foreign coastline less than $400 \mathrm{~nm}$ from the study site (e.g., Kerguelen and Heard Is. in the southern Indian Ocean show compressed EEZ widths at their opposing sides), putting shorter-range penguins across EEZs. All these special cases nevertheless reflect the reality of current political biogeography.

Besides, some species breed at more sites than others, thus providing more opportunities to cross jurisdictions. Similarly, at-sea movements have been studied more (or at all) for certain species, life-cycle stages and sites, than others: nevertheless, this aligned well with the objective of this study to reflect the current state of knowledge. 


\section{Penguins' long-range movements across genera}

We examined a total of 131 documents, providing information on penguins' at-sea distribution for a combination of 254 populations/stages, across all 18 species (Table S1). Long-range movements were documented in 16 species ( $89 \%$ of penguin species; Table 1), spread across all extant genera except Megadyptes (Fig. S1). Such movements lead the penguins across different marine regions, or even oceans (Fig. 1). In brush-tailed penguins (genus Pygoscelis), remarkably large-scale movements were observed across all three lifecycle stages, with a record of 4,124 km reached from the nest by a wintering chinstrap penguin (P. antarctica, [31]). Some Adélie penguin $P$. adeliae populations appeared rather sedentary however throughout the non-breeding period [54], and so were most of the non-breeding adult gentoo penguins $P$. papua, which only partially migrate otherwise [30]. In contrast, all adult crested penguins (genus Eudyptes) that have been studied during non-breeding phases have consistently shown spectacular migrations. For example, pre-moulting Fiordland penguins E. pachyrhynchus show return trips extending up to 2,288 $\mathrm{km}$ [44], and southern rockhopper penguins $E$. chrysocome may move $>3,500 \mathrm{~km}$ from their colony after moult, to the open ocean [37]. However, juvenile dispersal in crested penguins remains virtually unknown. In this respect, the greatest juvenile dispersals have been observed in the large-sized emperor and king penguins (Aptenodytes forsteri and A. patagonicus, respectively): satellite tracking showed juveniles reaching at least 3,503 and 4,783 km away from their nest, with minimum distances travelled totalling 7,794 and 11,712 km in each species, respectively $[23,26]$. The banded penguins (genus Spheniscus) undertake more modest-range migrations (reaching 1000-2000 km in postmoulting Humboldt S. humboldti, Magellanic S. magellanicus and juvenile African S. demersus penguins [47, 48, 51]). As in the little penguin Eudyptula minor (ranging up to $>500 \mathrm{~km}$; [53]), these long-range movements generally remained closer to the shore than in other genera.

\section{Evidence of transboundary movements}

The penguins' long-range movements were largely transboundary: among the 16 long-ranging species, there was evidence for individuals reaching beyond their initial EEZ in 14 of them (Fig. S1). Transboundary movements have thus been documented in the majority of penguin species (78\%), and despite the fact that in two species (the royal $E$. schlegeli and erect-crested E. sclateri penguins), little data is available yet on the birds' at-sea distribution. the South African to the Namibian EEZs [51]. Similarly, juvenile gentoo penguins $P$. papua may move from the French to the Australian EEZs in the southern Indian Ocean [35]. 
Most importantly, the literature provided at least 120 cases of penguins using ABNJ, across 13 species. For example, macaroni E. chrysolophus and Fiordland penguins undertake remarkable migrations reaching oceanic habitats in ABNJ, during both pre- and post-moult phases [37, 45]. More penguin species were found to reach the ABNJ than to move across EEZs: this may be because some species (e.g., E. moseleyi) breed exclusively on remote oceanic islands surrounded by $\mathrm{ABNJ}$ and where no other EEZ extends nearby. Besides, in 11 species (among Aptenodytes, Pygoscelis, Eudyptes and Spheniscus genera) we found evidence of both types of transboundary movements, across EEZs and to ABNJ.

Species richness across $A B N J$ Across their long-range movements, penguins distributed in most oceanic areas south of $37^{\circ} \mathrm{S}$ (Fig. 2). Each ABNJ sector harboured 2-10 species (predominantly 6-7), and 0-5 species per year quarter (predominantly 4; Table S2). The highest annual diversity (10 species) was found in ABNJ sector 2: north of the Polar Front, from the Eastern Indian Ocean to New Zealand (Fig. S2), with 3-4 species in each quarter. Also, ABNJ bordering South America (sector 4 ) held notably high diversity year-round ( 8 species; predominantly 5 during each quarter). Opposite, the lowest number of species known to exploit ABNJ was found in sector 3 (Pacific region: 2 species), with only $0-1$ species depending on the season. Species richness in any ABNJ sector remained 0-5 across seasons (predominantly 4-5 species); cases with nil known richness occurred only in quarters 1 and 4 , matching most species' breeding season.

\section{ABNJ use across stages}

Adult non-breeding phases consistently provided the most cases of long-range movements ( $\mathrm{n}=13$ species), multi-

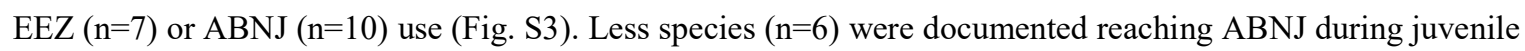
dispersal, however this possibly reflects a lower number of studies focusing on this life-cycle stage. Importantly, in eight species, the birds moved extensively even during the breeding season. This included seven species reaching ABNJ while breeding. For example, in king penguins foraging trips can last several weeks during chick-rearing, and coherently, the birds can repeatedly reach the high seas (and other EEZs) throughout the breeding season [16, 25], in addition to non-breeding phases [26, 27]. The king penguin is thus a clear example of species using ABNJ yearround. More surprisingly, use of ABNJ during the breeding season was also documented in smaller-sized species. Adélie and Magellanic penguins reach the high seas while breeding [30, 49], and among eudyptids so do the macaroni, royal and both species of rockhopper penguins [35, 39, 41]. It is thus remarkable that at least these seven species are known to reach $\mathrm{ABNJ}$ when their movement range is highly constrained.

\section{Challenges and opportunities for penguin conservation in ABNJ} In this paper we highlight that most penguin species have remarkable capacities of long-range movements to ABNJ, across regions and seasons: penguins are thus potentially at risk from human activities developing there. 
penguins. In particular, better coordinating the regulation of potentially harmful human activities at sea, and facilitating the creation of protected areas in southern ABNJ would likely benefit to penguin conservation.

\section{Current challenges to implement ABMTs in the high seas}

Experience shows that MPAs and other ABMTs may effectively benefit to marine wildlife, including penguins (e.g., [55]). Implementing such protective measures has long been requested in ABNJ as well, to protect a variety of mobile species such as penguins $[7,14,56]$. However, the current international legal framework does not fully provide for the creation of ABMTs in the high seas [57], and consequently the few MPAs existing in ABNJ are implemented under different institutional regimes [8]. Therefore a very fist challenge, from a governance perspective, is dealing with legal fragmentation $[8,58]$. Indeed, the UNCLOS addresses the conservation of living resources within EEZs (Article 61) but lacks mechanisms for establishing MPAs in the high seas (Part VII, Section 2). The 1992 UN Convention on Biological Diversity also provides a mechanism to implement ABMTs, but it is generally not applicable beyond national jurisdiction. Consequently, the main legal levers currently available for restricting access to certain areas of the high seas are regionally-based [8]: Regional Fisheries Management Organizations (RFMOs), regional environmental protection conventions with authority in ABNJ (e.g., in Antarctic waters the Convention on the Conservation of Antarctic Marine Living Resources - CCAMLR); or global, across ABNJ: e.g. the International Seabed Authority and the International Maritime Organization through the International Convention for the Prevention of Pollution from Ships (MARPOL).

The fact that the existing framework for the management of ABNJ is fragmented, uneven and uncoordinated, currently results in a sub-optimal management regime, with the above organisations having overlapping mandates but showing little cooperation or coherence between them [57]. Notably, fragmented governance may prevent or impede collaboration between organizations to monitor and enforce the designated areas in the high seas (e.g., boat or plane patrols); it may also be the cause for RFMOs to often be slow or reluctant to follow the advice of their science advisory bodies on ABMTs [8]. An overarching authority coordinating a precautionary approach to managing anthropic activities in ABNJ would hence likely result in better preserving biodiversity in the high seas.

Second, the legitimacy of prioritizing nature conservation over human use, when designating large protection areas, can be questionable, notably if people's subsistence depends on activities in that area [59]. These social justice implications are less prevalent in the high seas, however coexistence of humans and living species is at the centre of the ecosystemic approach, a key avenue for a successful marine governance [60] and one of the principles included in article 5 of the draft Treaty. This tension is reflected in part VII of UNCLOS, dedicated to the high seas. In fact "freedom of the high seas" (art. 87 of UNCLOS), which includes freedom of navigation, overflight, to lay submarine cables and pipelines, to construct artificial islands, fishing and scientific research, is the objective of most of its provisions, whereas the conservation and management of the living resources of the high seas, comes only as a second section and starts with the right to fish (art. 116). In sum, designating ABMTs should not undermine the mandate of the UNCLOS, establishing undeniable freedom-of-navigation rights in ABNJ. 
Last, there is the scientific challenge to identify the key utilized areas across time and taxa, within immense distribution ranges of mobile marine species [7, 9]. Current research on migratory connectivity in the oceans, identifying nodes of distribution aggregation and biological corridors between nodes, aims to promote the inclusion of such connectivity in the design of ocean conservation and management measures (e.g., [2]). Yet, information for many migratory taxa is currently insufficient or lacking.

Expected progresses from the treaty

Negotiations over an ILBI to preserve marine biodiversity in ABNJ cover a 'Package Deal' of four issues: marine genetic resources; ABMTs; conducting environmental impact assessments (EIAs); and capacity-building and the transfer of marine technology. The stakes are high, and the treaty thus brings "high hopes for the high seas" [61]: international cooperation is expected in order to adopt an ambitious, effective and equitable treaty with strong global oversight. Most importantly, negotiations for the ILBI provide an opportunity to fill the legal gap for implementing high sea ABMTs, notably by providing an authority and/or a framework for coordinating the needed scientific research in $\mathrm{ABNJ}$ [57].

The current draft (reviewed in [62]) includes in its general provisions (Part I) the precautionary approach to the exploitation of biodiversity in the high seas (draft Article 5), and the principle of common heritage of mankind to protect. These principles seem crucial to reach the long-term conservation objective stated in draft Article 2 and, if applied, would clearly improve the management of human activities in ABNJ. Regarding ABMTs (Part III), draft Article 15 further requires State Parties to promote coherence and complementarity in establishing ABMTs, which may help tackling the challenges associated with the current fragmented governance framework. Importantly, with the aim to centralize information and discussions, draft Article 19 gives the Conference of Parties (COP) responsibility for the decision-making process. In some cases the COP could recommend that State Parties promote the adoption of management measures; and the COP itself could take decisions on the adoption of such measures where there are no relevant legal instruments, frameworks or bodies [62]. In this regard, the governance structure foreseen in the draft treaty is much alike the UNFCCC (United Nations Framework Convention on Climate Change) one.

Another important progress may be achieved thanks to cooperation and technology transfer (Part IV). Remote surveillance of fisheries, from satellites [63] and other technological advances (e.g., [64]), is developing quickly and may become a key to monitoring and enforcing MPAs in ABNJ. Promoting capacity-building and technology transfer may thus facilitate effective, global monitoring of designated ABNJ through new technologies [8]. Regarding Institutional arrangements (Part VI), it is detailed that a scientific and technical body will provide advice on the four elements of the Package Deal (draft Article 49): this would also help to implement new ABMTs. However, some elements in the current draft treaty may not be sufficiently ambitious to deliver an optimal, effective governance framework [62]. For example, in Part IV (EIAs), the draft treaty may require to all activities that have an impact in ABNJ, to conduct an EIA; but without detailing whether this would be only advisory, or whether States 
Parties or the COP would ultimately decide or provide authorizations for such activities. Also up to now, the COP has not been awarded the general power to take binding decisions.

\section{1}

282

283

\section{A giant leap for penguin conservation?}

Considering the prevalence of their long-range movements emphasized in this study, penguins are remarkably little represented in the 1979 Convention on the Conservation of Migratory Species of Wild Animals (Bonn Convention; CMS): only Humboldt (Appendix I) and African (Appendix II) penguins are included. This early intergovernmental treaty, under the aegis of the United Nations Environmental Programme, aimed to preserve migratory wildlife and their habitats worldwide; however, it is of little help for threatened penguins migrating across ABNJ (Table 1). The new treaty on $\mathrm{ABNJ}$ may better benefit to penguins and facilitate their conservation against an array of threats at sea. We identify below a few elements directly applicable to penguins in the context of one threat: fisheries.

First, the treaty may provide authority to develop ABMTs in areas with fragmented governance. For example, hotspots of trawl fishing effort were highlighted in ABNJ off southeast Argentina, an ocean sector devoid of specific RFMO or fisheries management body [63], but with high penguin species richness (Fig. 2). Among the penguin species using this area, at least four (A. patagonicus, E. chrysolophus, E. chrysocome and S. magellanicus) are known bycatch in the neighbouring domestic fisheries [15]. Importantly, these four species are found as bycatch in all four fishing gear types examined in the region (trawl, gillnet, purse seine, longline; [15]), which closely match the four most operated ones in the ABNJ (longline, purse seine, squid jigging, and trawl; [65]). It is thus very likely that at least these four species are bycaught by high sea fisheries, at least in this area. The new ILBI may empower the COP to manage fisheries in this area, and the COP could in turn propose to implement ABMTs in such areas where unclear governance and high fishing effort correlate with severe mortality risk for several penguin species.

Second, even in areas where governance for environmental management is clearer, the treaty may bring overarching authority to take decisions on ABMTs in the high seas when science-based evidence is available. For example, in 2011 CCAMLR adopted a legally-binding Conservation Measure on establishing MPAs. Since then, several MPA proposals have been submitted (e.g., in East Antarctica), but most have been unsuccessful due to political and fishing interests in the Southern Ocean [8]. In such cases when fisheries' interests impede the development of ABMTs against science-based evidence, the new ILBI seems likely to help abiding to scientific recommendations. Outside the CCAMLR application area, important areas used by endangered penguins were also highlighted, that do not overlap any existing MPA [9]; however the designation of a large MPA in this region is not achievable by single neighbouring States. In this case again, the overarching authority of the COP could directly recommend the RFMO to adjust fisheries management to implement a new ABMT in the region.

And third, the core principles set in this treaty are an opportunity to implement a more precautionary approach for the exploitation of ABNJ [8]. Currently, fisheries are one of the major threats to penguin conservation at sea (albeit possibly not for all species), through indirect effects such as resource competition, and direct mortality reported 
notably from domestic gillnet fisheries $[14,15,66]$. In contrast, penguins moving to ABNJ may seem to exploit oceanic deserts devoid of human activity [44], but the severity of the impacts that high seas fisheries have or will have on penguins is largely unknown. Precautionary measures to protect penguins in ABNJ seem particularly valid, for several reasons. First, penguins are long-lived animals with low reproductive rates, which makes their populations particularly vulnerable to chronic impacts on their survival or reproductive success, with long recovering processes [56]. Second, penguins are marine predators, and thus protecting the main areas they use has top-down effects translating into preserving the resource and food webs they depend on [7]. Third, industrial fisheries are expanding and intensifying in $\mathrm{ABNJ}[6,63]$. Fourth, there are significant levels of illegal fishing detected in the high seas [64]. And fifth, studies [67, 68] show that the RFMOs have somewhat failed to (1) prevent stocks' overexploitation, (2) assess compliance to regulations, (3) produce transparent data on fishing effort and bycatch in ABNJ and (4) achieve sufficient coverage of fisheries by onboard observers to assess the efficacy of bycatch mitigation measures. Therefore, in line with the precautionary approach underlined in its general provisions, the new treaty is an opportunity to implement in $\mathrm{ABNJ}$ a network of areas with preventively restricted human use, aiming to preserve the feeding habitats used by mobile species such as penguins, before impacts on their populations would appear or aggravate. Our study supports that protected areas designated in $\mathrm{ABNJ}$ south of $35^{\circ} \mathrm{S}$ would predominantly be used by a diversity of penguins regardless of season (with the exception of the Pacific sector north of the Polar Front, during summer). Studies showed the disproportionate value of very large-scale MPAs to global marine conservation targets, despite potential social justice concerns [59,69]. Our results based on ecological indicator species may hence guide the designation of such large-scale protection areas in $\mathrm{ABNJ}$, following a precautionary approach in a context of growing human footprint [6].

\section{Conclusions}

The expansion of ocean uses, especially in the high seas, has rapidly outpaced the development of scientific knowledge on marine wildlife distribution and ecosystem resilience capacities [5,6]. Yet, knowledge on marine animals' at-sea movements is crucial to improve the management of biodiversity at the national and international levels [19]. In this work we highlight that transboundary movements, notably to the high seas, are remarkably prevalent among penguin species, for which human activities conducted in ABNJ can be major threats. Therefore, penguin conservation seems deeply intertwined with the development of the new ILBI to protect biodiversity in ABNJ. This ambitious treaty is notably expected to strengthen existing governance frameworks, and to place cooperation and science at the core of the management regime for this vast global commons [61]. Taking advantage of technological advances allowing to adequately monitor vast regions in $\mathrm{ABNJ}[6,63,64]$, new policies developed under this treaty could hence be extremely effective for the conservation of penguins and their habitats at sea, with less potential socio-economic harm than in domestic waters. Applied to penguin conservation, the treaty and its envisioned ecosystemic and precautionary approaches may provide the needed structure to implement a network of large ABMTs in the most used ABNJ across species $[2,7]$. 
Further analyses will be required to identify which sectors exactly are a priority [9], and expanding tracking studies is also needed to fully grasp the extent to which penguin may use ABNJ across species, sites and life-cycle stages. Public outreach has proven to be a key dimension of the UNFCCC COPs [70] and may also be crucial to the success of this new treaty [8]. Highlighting oceanic migrations through charismatic animals such as penguins may represent a unique way to harness public concern for the conservation of this common heritage of mankind. Finally, the negotiations over this treaty will serve as a new opportunity to attempt and effectively preserve marine biodiversity in $\mathrm{ABNJ}$, knowing that one remaining alternative could be the total closure of high seas to activities of extraction. Modelling studies [71] showed that closing high seas to fishing would induce cooperation among countries in the exploitation of migratory resource stocks and provide a refuge sufficiently large to recover stock levels, thereby greatly increasing fisheries profit, fisheries yields, and fish stock conservation. Reduced impacts on non-target species, including penguins, would likely follow from such restrictions. It is thus crucial to keep in mind that the success or failure of the new treaty in the long-term will be measured against such alternatives: this should allow stakeholders to re-evaluate whether the exploitation of global commons through industrial, not always economically viable activities [65], is ecologically sustainable.

\section{Acknowledgements}

The authors declare they have no conflict of interest.

\section{References}

1 Harrison AL, Costa DP, et al. (2018) The political biogeography of migratory marine predators. Nature Ecol. Evol., 2(10), 1571-1578.

2 Dunn DC, Harrison AL, et al. (2019) The importance of migratory connectivity for global ocean policy. Proc. R. Soc. B, 286(1911), 20191472.

3 Gjerde KM, Dotinga H, Hart S, Molenaar EJ, Rayfuse R, Warner R (2008) Regulatory and governance gaps in the international regime for the conservation and sustainable use of marine biodiversity in areas beyond national jurisdiction. IUCN, Gland.

4 Merrie A, Dunn DC, et al. (2014) An ocean of surprises-trends in human use, unexpected dynamics and governance challenges in areas beyond national jurisdiction. Glob. Environ. Change, 27, 19-31.

5 Ban NC, Bax NJ, et al. (2014) Systematic conservation planning: a better recipe for managing the high seas for biodiversity conservation and sustainable use. Conserv. Lett., 7(1), 41-54.

6 Kroodsma DA, Mayorga J, et al. (2018) Tracking the global footprint of fisheries. Science, 359(6378), 904-908.

7 Lascelles B, Notarbartolo-Di-Sciara G, et al. (2014) Migratory marine species: their status, threats and conservation management needs. Aquatic Conserv.: Mar. Freshw. Ecosyst., 24(S2), 111-127.

8 De Santo EM (2018) Implementation challenges of area-based management tools (ABMTs) for biodiversity beyond national jurisdiction (BBNJ). Mar. Policy, 97, 34-43.

9 Dias MP, Oppel S, et al. (2017) Using globally threatened pelagic birds to identify priority sites for marine conservation in the South Atlantic Ocean. Biol. Conserv., 211, 76-84.

10 Wynne B (1992) Uncertainty and Environmental learning. Reconceiving science and policy in the preventive paradigm. Glob. Environ. Chang., 6(1), 111-127.

11 De Santo EM, Ásgeirsdóttir Á, et al. (2019) Protecting biodiversity in areas beyond national jurisdiction: An earth system governance perspective, Earth Syst. Gov., 2, 100029.

12 Barkley AN, Gollock M, et al. (2019) Complex transboundary movements of marine megafauna in the Western Indian Ocean. Anim. Conserv., 22(5), 420-431.

13 Dias MP, Martin R, et al. (2019) Threats to seabirds: a global assessment. Biol. Conserv., 237, 525-537. 
14 Trathan PN, García- Borboroglu P, et al. (2015) Pollution, habitat loss, fishing, and climate change as critical threats to penguins. Conserv. Biol., 29(1), 31-41.

15 Crawford R, Ellenberg U, et al. (2017) Tangled and drowned: a global review of penguin bycatch in fisheries. Endang. Species Res., 34, 373-396.

16 Jouventin P, Capdeville D, Cuenot-Chaillet F, Boiteau C (1994) Exploitation of pelagic resources by a nonflying seabird: satellite tracking of the king penguin throughout the breeding cycle. Mar. Ecol. Prog. Ser., 106, 11-19.

17 Kooyman GL, Kooyman TG, Horning M, Kooyman CA (1996) Penguin dispersal after fledging. Nature, 383(6599), 397-397.

18 Wilson RP, Culik BM, Kosiorek P, Adelung D (1998) The over-winter movements of a chinstrap penguin (Pygoscelis antarctica). Polar Rec., 34(189), 107-112.

19 Hays GC, Bailey H, et al. (2019) Translating marine animal tracking data into conservation policy and management. Trends Ecol. Evol., 34(5), 459-473.

20 Guinard E, Weimerskirch H, Jouventin P (1998) Population changes and demography of the northern Rockhopper Penguin on Amsterdam and Saint Paul Islands. Col. Waterbirds, 21, 222-228.

21 García-Borboroglu P, Boersma PD (eds.) (2013) Penguins: natural history and conservation. University of Washington Press.

22 Wienecke B, Kirkwood R, Robertson G (2004) Pre-moult foraging trips and moult locations of emperor penguins at the Mawson Coast. Polar Biol., 27(2), 83-91.

23 Labrousse S, Orgeret F, et al. (2019) First odyssey beneath the sea ice of juvenile emperor penguins in East Antarctica. Mar. Ecol. Prog. Ser., 609, 1-16.

24 Ancel A, Kooyman GL, et al. (1992) Foraging behaviour of emperor penguins as a resource detector in winter and summer. Nature, 360(6402), 336-339.

25 Pütz K (2002) Spatial and temporal variability in the foraging areas of breeding king penguins. Condor, 104(3), 528-538.

26 Pütz K, Trathan PN, Pedrana J, Collins MA, Poncet S, Lüthi B (2014) Post-fledging dispersal of king penguins (Aptenodytes patagonicus) from two breeding sites in the South Atlantic. PLoS One, 9(5), e97164.

27 Orgeret F, Weimerskirch H, Bost CA (2016) Early diving behaviour in juvenile penguins: improvement or selection processes. Biol. Lett., 12(8), 20160490.

28 Clarke J, Kerry K, Fowler C, Lawless R, Eberhard S, Murphy R (2003) Post-fledging and winter migration of Adélie penguins Pygoscelis adeliae in the Mawson region of East Antarctica. Mar. Ecol. Prog. Ser., 248, 267278.

29 Ballard G, Toniolo V, Ainley DG, Parkinson CL, Arrigo KR, Trathan PN (2010) Responding to climate change: Adélie penguins confront astronomical and ocean boundaries. Ecology, 91(7), 2056-2069.

30 Hinke JT, Cossio AM, Goebel ME, Reiss CS, Trivelpiece WZ, Watters GM (2017) Identifying risk: concurrent overlap of the Antarctic krill fishery with krill-dependent predators in the Scotia Sea. PLoS One, 12(1), $\mathrm{e} 0170132$.

31 Hinke JT, Santos MM, Korczak-Abshire M, Milinevsky G, Watters GM (2019) Individual variation in migratory movements of chinstrap penguins leads to widespread occupancy of ice-free winter habitats over the continental shelf and deep ocean basins of the Southern Ocean. PLoS One, 14(12), e0226207.

32 Biuw M, Lydersen C, De Bruyn PN, Arriola A, Hofmeyr GG, Kritzinger P, Kovacs KM (2010) Long-range migration of a chinstrap penguin from Bouvetøya to Montagu Island, South Sandwich Islands. Antarct. Sci., 22(2), 157-162.

33 Enticott JW (1986) Distribution of penguins at sea in the southeastern Atlantic and southwestern Indian Oceans. Cormorant, 13, 118-142.

34 Reid TA, Hull CL, Eades DW, Scofield RP, Woehler EJ (1999) Shipboard observations of penguins at sea in the Australian sector of the Southern Ocean, 1991-1995. Mar. Ornithol., 27, 101-110.

35 Thiebot JB, Lescroël A, Pinaud D, Trathan PN, Bost CA (2011) Larger foraging range but similar habitat selection in non-breeding versus breeding sub-Antarctic penguins. Antarct Sci., 23(2), 117-126.

36 Harris S, Scioscia G, Pütz K, Mattern T, Rey AR (2020) Niche partitioning between coexisting gentoo Pygoscelis papua and Magellanic penguins Spheniscus magellanicus at Martillo Island, Argentina. Mar. Biol., 167(8), 1-10. 
37 Thiebot JB, Cherel Y, Crawford RJ, Makhado AB, Trathan PN, Pinaud D, Bost CA (2013) A space oddity: geographic and specific modulation of migration in Eudyptes penguins. PLoS One, 8(8), e71429.

38 Ratcliffe N, Crofts S, et al. (2014) Love thy neighbour or opposites attract? Patterns of spatial segregation and association among crested penguin populations during winter. J. Biogeogr., 41(6), 1183-1192.

39 Hull CL (1999) The foraging zones of breeding royal (Eudyptes schlegeli) and rockhopper (E. chrysocome) penguins: an assessment of techniques and species comparison. Wildl. Res., 26(6), 789-803.

40 Pütz K, Ingham RJ, Smith JG, Lüthi BH (2002) Winter dispersal of rockhopper penguins Eudyptes chrysocome from the Falkland Islands and its implications for conservation. Mar. Ecol. Prog. Ser., 240, 273-284.

41 Heerah K, Dias MP, Delord K, Oppel S, Barbraud C, Weimerskirch H, Bost CA (2019) Important areas and conservation sites for a community of globally threatened marine predators of the Southern Indian Ocean. Biol. Conserv., 234, 192-201.

42 Thompson DA (2016) Penguins reveal unknown swimming talents. NIWA media release. Available at: https://www.niwa.co.nz/news/penguins-reveal-unknown-swimming-talents

43 Speedie C (1992) An erect-crested penguin in the southern Indian Ocean. Notornis, 39(1), 58-60.

44 Mattern T, Pütz K, et al. (2018) Marathon penguins-Reasons and consequences of long-range dispersal in Fiordland penguins/Tawaki during the pre-moult period. PLoS One, 13(8), e0198688.

45 Thiebot JB, Bost CA, Poupart T, Filippi D, Waugh S (2020) Extensive use of the high seas by Vulnerable Fiordland penguins across non-breeding stages, J. Ornithol., doi: 10.1007/s10336-020-01791-8.

46 Culik BM, Luna-Jorquera G (1997) The Humboldt penguin Spheniscus humboldti: a migratory bird?. J. Ornithol., 138(3), 325-330.

47 Pütz K, Raya Rey A, Hiriart-Bertrand L, Simeone A, Reyes-Arriagada R, Lüthi B (2016) Post-moult movements of sympatrically breeding Humboldt and Magellanic Penguins in south-central Chile. Glob. Ecol. Conserv., 7, 49-58.

48 Pütz K, Ingham RJ, Smith JG (2000) Satellite tracking of the winter migration of Magellanic Penguins Spheniscus magellanicus breeding in the Falkland Islands. Ibis, 142(4), 614-622.

49 Pütz K, Ingham RJ, Smith JG (2002) Foraging movements of Magellanic penguins Spheniscus magellanicus during the breeding season in the Falkland Islands. Aquat. Conserv. Mar. Freshw. Ecosyst., 12(1), 75-87.

50 Pütz K, Schiavini A, Raya Rey A, Lüthi BH (2007) Winter migration of magellanic penguins (Spheniscus magellanicus) from the southernmost distributional range. Mar. Biol., 152(6), 1227-1235.

51 Sherley RB, Ludynia K, et al. (2017) Metapopulation tracking juvenile penguins reveals an ecosystem-wide ecological trap. Curr. Biol., 27(4), 563-568.

52 Harding CT (2014) Tracking African penguins (Spheniscus demersus) outside of the breeding season: Regional effects and fishing pressure during the pre-moult period (Doctoral dissertation, University of Cape Town).

53 Weavers BW (1992) Seasonal foraging ranges and travels at sea of Little Penguins Eudyptula minor, determined by radiotracking. Emu, 91(5), 302-317.

54 Black C, Southwell C, Emmerson L, Lunn D, Hart T (2018) Time-lapse imagery of Adélie penguins reveals differential winter strategies and breeding site occupation. PLoS One, 13(3), e0193532.

55 Pichegru L, Grémillet D, Crawford RJM, Ryan PG (2010) Marine no-take zone rapidly benefits endangered penguin. Biol. Letters, 6(4), 498-501.

56 Yorio P (2009) Marine protected areas, spatial scales, and governance: implications for the conservation of breeding seabirds. Conserv. Lett., 2(4), 171-178.

57 Wright G, Gjerde KM, et al. (in press) Marine spatial planning in areas beyond national jurisdiction. Mar. Policy.

58 Biermann F, Pattberg P, Van Asselt H, Zelli F (2009) The fragmentation of global governance architectures: A framework for analysis. Glob. Environ. Politics, 9(4), 14-40.

59 De Santo EM (2013) Missing marine protected area (MPA) targets: how the push for quantity over quality undermines sustainability and social justice. J. Environ. Manage., 124, 137-146.

60 Langlet D, Rayfuse R (2019) Challenges in Implementing the Ecosystem Approach: Lessons Learned. Publications on Ocean Development, 87, 445-461.

61 Wright G, Cremers K, et al. (2019) High Hopes for the High Seas: beyond the package deal towards an ambitious treaty. IDDRI, Issue Brief, 01/19. 
62 Cremers K, Rochette J, Wright G, Gjerde K, Harden-Davies H (2020) A preliminary analysis of the draft high seas biodiversity treaty. IDDRI, Study, 01/20.

63 Dunn DC, Jablonicky C, et al. (2018) Empowering high seas governance with satellite vessel tracking data. Fish Fish., 19(4), 729-739.

64 Weimerskirch H, Collet J, et al. (2020) Ocean sentinel albatrosses locate illegal vessels and provide the first estimate of the extent of nondeclared fishing. Proc. Natl. Acad. Sci. USA, 117(6), 3006-3014.

65 Sala E, Mayorga J, et al. (2018) The economics of fishing the high seas. Sci. Adv., 4(6), eaat2504.

66 Cardoso LG, Bugoni L, Mancini PL, Haimovici M (2011) Gillnet fisheries as a major mortality factor of Magellanic penguins in wintering areas. Mar. Pollut. Bull., 62, 840-844.

67 Cullis-Suzuki S, Pauly D (2010) Failing the high seas: a global evaluation of regional fisheries management organizations. Mar. Policy, 34(5), 1036-1042.

68 Gilman E, Passfield K, Nakamura K (2014) Performance of regional fisheries management organizations: ecosystem- based governance of bycatch and discards. Fish Fish., 15(2), 327-351.

69 Toonen RJ, Wilhelm TA, et al. (2013) One size does not fit all: the emerging frontier in large-scale marine conservation. Mar. Pollut. Bull., 77(1-2), 7-10.

70 Stevenson H, Dryzek JS (2014) Democratizing global climate governance. Cambridge University Press.

71 White C, Costello C (2014) Close the high seas to fishing? PLoS Biol., 12(3), e1001826. 

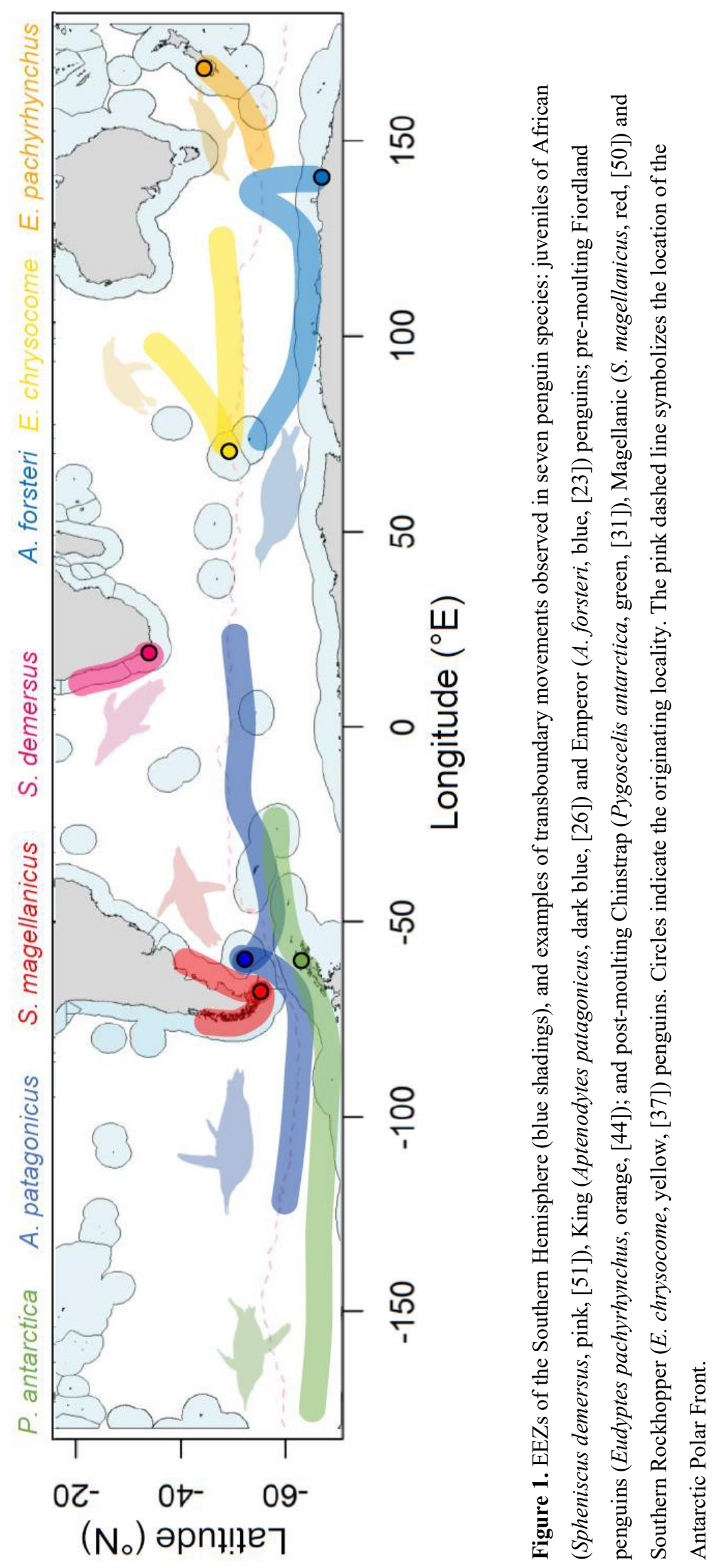

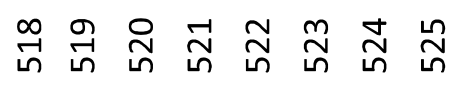




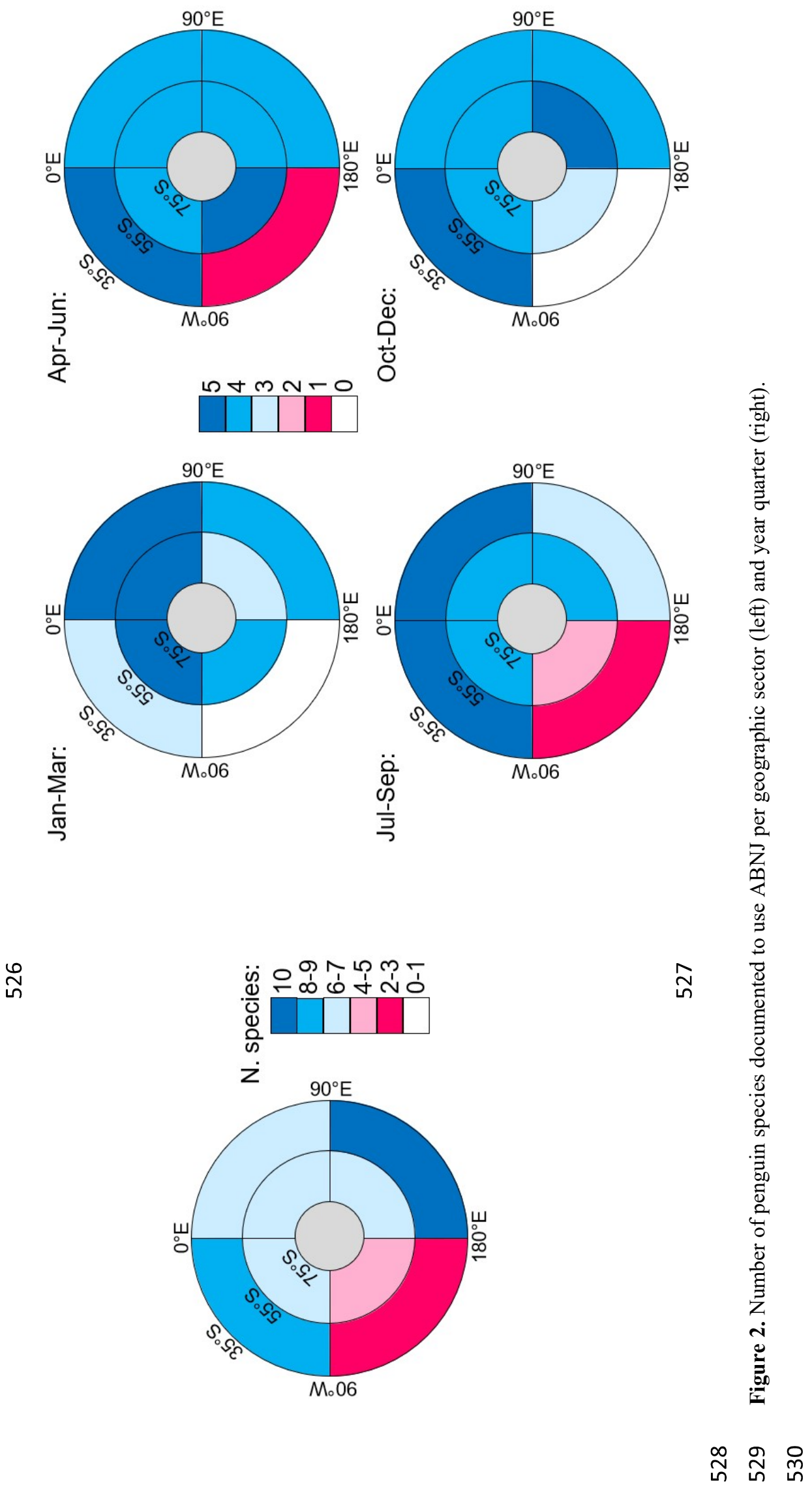




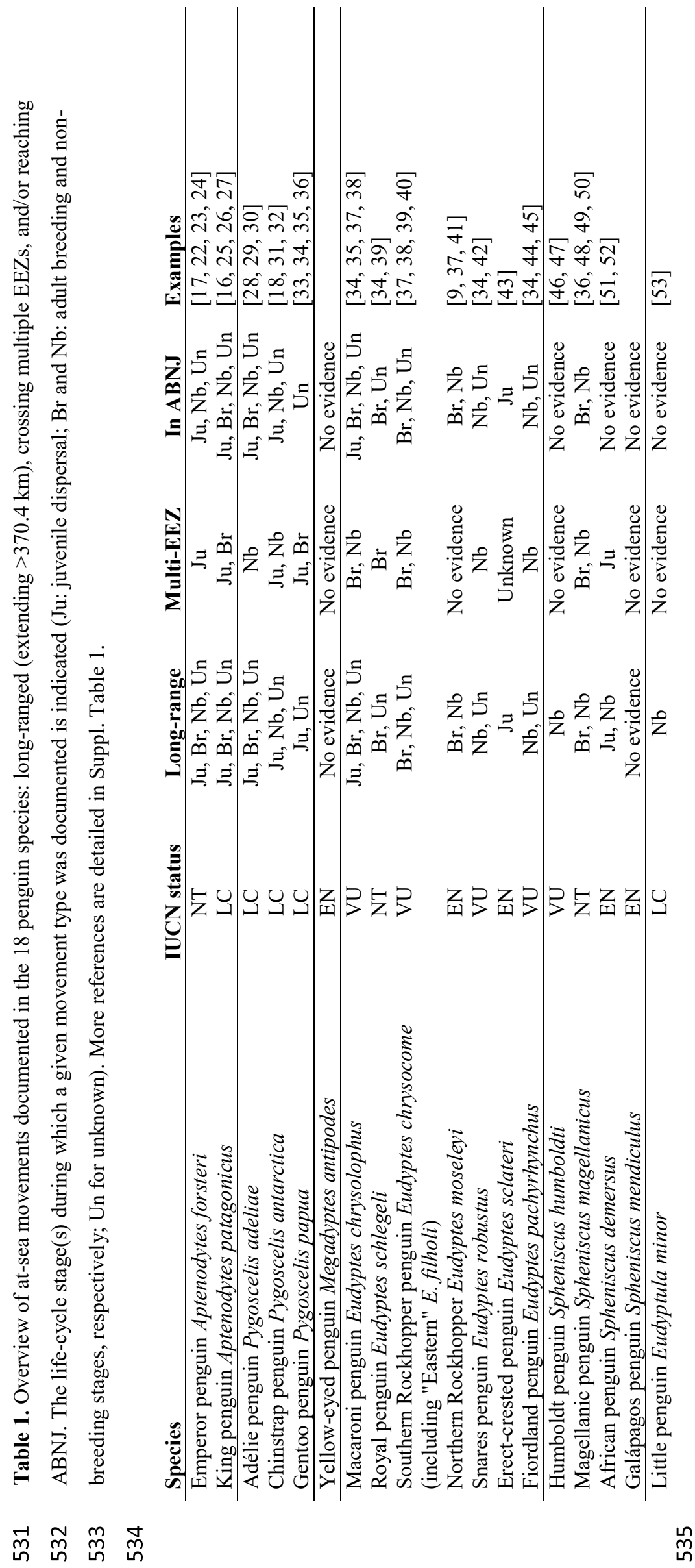




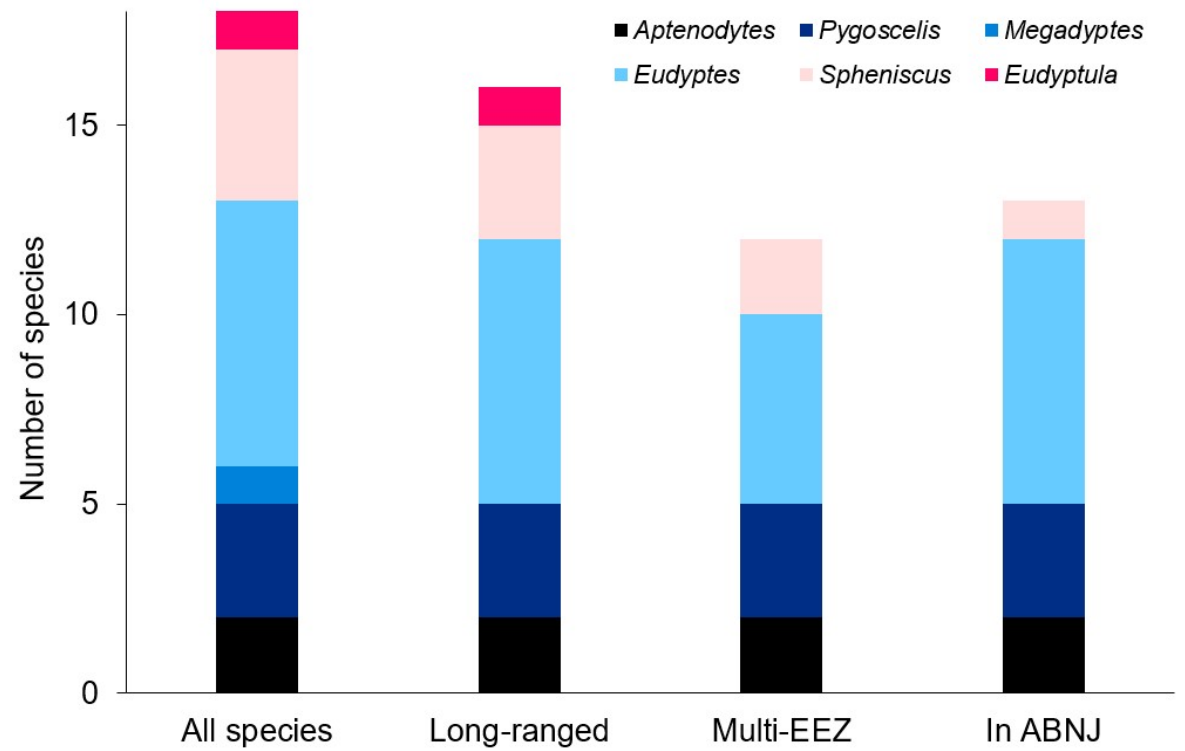

Supplementary Figure S1. Number of penguin species within each genus ( $\mathrm{n}=18$ species), in which cases have been documented for movements of long range, crossing multiple EEZs and reaching ABNJ. Note that at-sea movements are little known in some species.

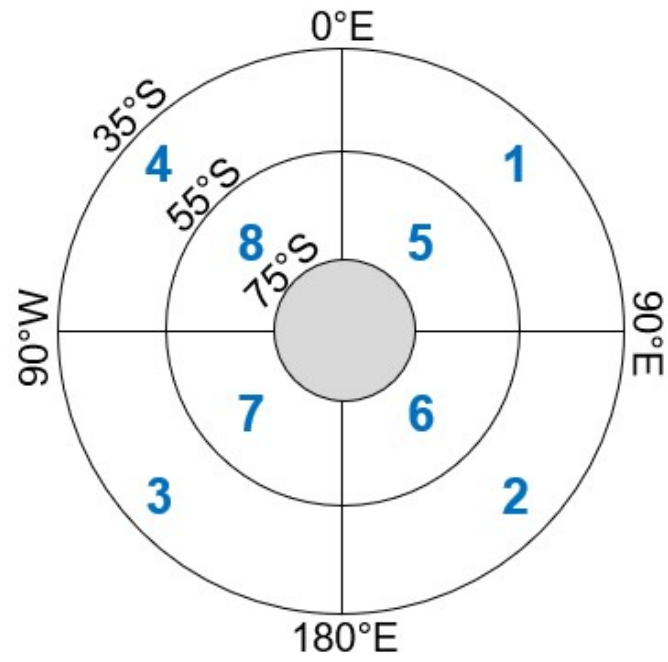

Supplementary Figure S2. Description of the geographic sectors used in Supplementary Tables $1 \& 2$. Sectors are numbered from 1 to 8 (blue digits), and cover the circumpolar area between $35^{\circ} \mathrm{S}$ and $75^{\circ} \mathrm{S}$. These latitudinal boundaries match the northernmost extent of penguin distribution in this study and the southernmost extent of ABNJ, respectively. The average latitude of the Antarctic Polar Front (c. 55 ${ }^{\circ}$ ) further separates sectors $1-4$ to the north, from sectors 5-8 to the south. 
Supplementary Figure S3. Number of penguin species within each life-cycle stage (Ju: juvenile dispersal; $\mathrm{Br}$ and $\mathrm{Nb}$ : adult breeding and non-breeding stages, respectively; Un for unknown), in which cases have been documented for movements: of long range, crossing multiple EEZs and reaching ABNJ. Note that at-sea movements are little known in some species.

Supplementary Table S1. (Excel file). Detailed results on penguins' at-sea movements, from all examined references ( $\mathrm{n}=131$ ). Geographic sectors ( $\mathrm{S} 1$ to $\mathrm{S} 8$ ) are spatially organized as shown on Fig. S2, and year quarters are as follow: January-March (Q1), April-June (Q2), July-September (Q3), and October-December (Q4). quarter (Q1 to Q4). 


\section{Conflict of Interest}

1 The authors declare they have no conflict of interest. 
Click here to access/download Supplementary Material Supplementary Table S1.xlsx 
Click here to access/download Supplementary Material Supplementary Table S2.xlsx 